\title{
Basic Needs and its Critics
}

\section{Dharam Ghai *}

In recent years the basic needs approach to devclopment has aroused a great deal of interest among planners and policy-makcrs in developing countries, the international development community, and donors, both bilateral and multilateral'. It received world-wide support at the World Employment Conference convened by the ILO in June 1976, when the member states agreed that "strategies and national development plans and policies should include explicitly as a priority objective the promotion of employment and the satisfaction of the basic needs of each country's population". The Conference adopted a Programme of Action which included a comprehensive and wide-ranging set of measures for the implementation of a basic needs strategy. Since then, the basic needs approach has been endorsed in several other fora, including the Economic and Social Council of the United Nations and the Non-Aligned Summit Conference held in Sri Lanka in September, 1976. The growing support for and endorsement of the basic needs approach has inevitably been accompanied, after an appropriate interval, by a rising tide of criticism which has come from many quarters and taken many forms. The purpose of this article is to consider the validity of some of the most frequent criticisms levelled against the basic needs approach. But before taking up specific criticisms, it may be useful to mention some other factors which are contributing to a general 'dislike' of the basic needs approach on the part of many persons and countries.

First, there is a tendency on the part of some individuals to merge the two concepts of the basic needs approach and the New International Economic Order (NIEO) and to argue that basic needs are the only valid or new elements in the NIEO. This is often a thinly disguised attack on the NIEO. It is, therefore, not surprising that many developing countries for whom the NIEO represents the culmination of their demands for the restructuring of the world economy should begin to regard pleas in favour of basic needs as diversionary tactics on the part of the opponents of the NIEO. It will be argued below that there are important inter-relationships

* The views expressed here are those of the author and not of the ILO where he is currently working.

1 The recent interest in these ideas owes much to the plans and policies of several countries. The following documents were also important: The Declaration of Cocovos (1974); What Now Anolher Development (1975): Employment Growth and Basio Neceds (1976); Cafustrophe or New Society? A Latin American World Model (1976) and Reshaping the Imfermational Order (1976). between the NIEO and the basic needs strategy, but attempts to substitute one for the other are both intellectually dishonest and politically harmful.

Second, many persons-and particularly 'established development economists --are irritated by the claims to originality made by converts to the basic needs doctrine. While the basic needs approach undoubtedly yields some useful insights and perspectives, it is of course preposterous to burden it with unsupportable claims of an entirely new approach to development. Not only are many of the ideas associated with the basic needs approach to be found in the past development plans and/or policies of several developing countries but the policy implications of such an approach have much in common with other 'new development strategies' such as those focusing on employment creation or redistribution with growth (the proponents or adherents of which. incidentally, have been no less vociferous in their claims of originality and, it would appear, with scarcely more justification).

A third factor which may have contributed to the recent chorus of criticism is the absence of an authoritative, comprehensive and definitive work dealing with the concepts, theories and strategies associated with a basic needs approach. The lack of a standard source has enabled people with divergent views and ideologies to advance a wide variety of policies, institutions and strategies as constituting the essence of the basic needs approach to development. While this eclecticism may have been an important factor in the quick and widespread acceptance of the basic needs approach, it has understandably not found favour with those who belicve in ideological purity and/or intellectual rigour.

In addition more specific criticisms have been levelled against this approach. Academically inclined critics have argued that it is lacking in scientific rigour, claiming that its 'objective function' is vague and diffuse and that it lacks a solid base of theoretical underpinnings. This in turn deprives its policy conclusions of much of their validity. There can be no doubt that there are a number of theoretical and empirical issues thrown up by the basic nceds discussion which need to be urgently investigated. These include such issues as the definition, measurement and quantification of basic needs; estimation and generation of resources to meet these needs; elaboration of the necessary productive systems and structures; and the political, administrative and economic problems of transition as the economies shift towards a bissic needs orientation. 
Some of the work underway in the ILO the World Bank and elscwherc is focused precisely on these issues. But to acknowledge the need for further work along these lines is not necessarily to agree with some of these theoretical criticisms. For often what these critics are asking for is a justification of the basic needs approach within the framework of neo-classical economics. This scems to be the case. for example. with some of the discussion that has been going on concerning the nature of the objective function implied by the basic needs approach. The terminology and the concepts used in basic needs discussion do not fit too easily in the neo-classical framework. Furthermore, the basic needs approach has tended to stress many non-conomic aspects such as human rights. participation. self-rcliance. etc. Economists trained in the neo-classical school find all this uncomfortable. if not downright distasteful. And many critics of this persuasion. in their attenpt to appraise all other approaches from the perspective of neo-classical economics. often overlook the crude utilitarianism which provides the philosophical foundation for many of its conclusions.

A different kind of criticism holds that the basic needs approach gives the impression that the elimination of poverty is all too casy. It is further argued that such an approach assumes away class and group conflicts and underestimates the extent of the structural and institutional changes necessary for an effective attack on poverty. Some then go on to argue that the failure of the basic needs approach is evidenced by the fact that few. if any. countrics have opted for it. In relation to criticisms of this sort. it needs first to be stated that virtually all the work on development emanating from dominant trends in Western cconomics is charactcriscd by a failure to integrate cconomic analysis with class and group conflicts. In this respect. the basic needs approach represcnts a step forward. for it stresses the key importance of structural change and mass participation in a strategy designed to meet the basic needs of the poor. It also recognises the primacy of the distribution of political power in determining development patterns. However. most expositions of basic needs contain only a rudimentary analysis of political power and class and group conflicts. Indecd this could hardly be otherwisc considcring that most recent work on basic needs has becn done in international agencies and even when initiated by individual scholars. it has becn addressed for the most part to governments. As for the criticism that the basic necds approach has thus far had very little impact on government policics, the first point to make is that it is much too carly to draw conclusions of this sort. Inded. from the seriousness with which this approach is being considesed by development agencies and at least some developing countries. it would appear that basic needs considerations are beginning to exert influence on policy too quickly. But more importantly. if it is the case that satisfaction of the basic needs of the masses within a short period of time can only be achieved by far-reaching structural changes. it would be naive to expect quick government implementation of such policies.

A pervasive criticism of a basic needs approach is that it is entirely consumption-oriented. that it represents 'social welfarism" in conditions of underdevelopment and thus it is biased against economic growth. It is indeed true that such an approach puts overwhelming emphasis on the satisfaction of the basic needs of the masses within the shortest possible period. and some of its proponents have given the impression that the merc redistribution of wealth and income will suffice to meet basic needs targets. Much of the development literature. both capitalist and Marxist. is characterised by a strong pro-growth and anti-consumption bias. To that extent. the basic needs approach represents a necessary and long overdue corrective. It also contains within it an inportant suggestion that very few socicties are so poor that with the necessary structural changes they are unable to mect the most basic material necds of their people. Having said this. it must be recognised that the basic needs aspirations of most devcloping countrics could not be attained without substantial and sustained economic grow'th. But to repeat what has often been pointed out in the past. what is important is not so much a given rate of growth as the pattern and character of that growth.

A rclated criticism often advanced by some developing and socialist countrics is that a basic needs strategy would perpetuate economic backwardness. It is pointed out that the basic needs approach stresses the production of consumer as opposed to capital goods. of agricultural commodities as against industrial goods. and recommends intermediate and antiquated rather than modern and advanced technology. As with some other criticisms considered carlier, it is possible that some versions of the basic needs approach may have justifiably provoked this criticism. especially in relation to discussions on technology. But it would be fallacious to argue that the logic of the basic needs approach favoul's agriculture. consumer goods and antiquated technology as opposed to industry. capital goods and modern technology. The basic needs approach is biased in favour of the production and appropriate distribution of the basket of basic goods and services. Its precise implications for the techniques of production, and the output mix in terms of consumer and capital. agricultural and industrial goods will depend on the situation in a particular country. Leaving aside trading possibilitics for the moment. it is cvident that in a country where the most basic of 
the basic needs are not satisfied and consequently large numbers suffer from inadequate nutrition, the central thrust of a basic needs strategy must be an allout effort to increase food production and ensure its appropriate distribution. But even in this situation it would be incorrect to argue that the basic needs approach stresses only the production of food. In order to step up the production of food, it will be necessary to overcome many bottlenecks. Depending upon the situation in a particular country, this may involve increased production of agricultural tools and machinery, fertilisers and pesticides, etc., and this in turn may call for reduction in the output of some other producer or consumer goods. This point can be generalised to other basic goods and services. In a typical country, the basket of basic goods and services would include such things as food, housing, books, paper, medical supplies, buses, lorries, bicycles, shoes, furniture, pots and pans, clothing, ctc., a list comprising both agricultural and industrial consumer goods. Furthermore, to produce such. goods and services, it is necessary to have intermediate and capital goods. It cannot, therefore, be the case that the basic needs approach is biased against the production of industrial and capital goods. This criticism can only be validated on the assumption that the basic needs approach advocates export of agricultural raw materials in exchange for imports of manufactured consumer and capital goods to satisfy the basic needs of the pcoplc. Needless to say, no such assumption is implied or required by a basic needs stratcgy. The presumption, if anything, must be in favour of reduced dependence on conventional trading patterns.

Likewise, there is nothing in the logic of the basic needs approach which militates against modern technology as long as it is socially profitable. In fact, it would seem that greater standardisation and larger production runs for basic goods would make it more profitable to use modern technology than is currently the case. But the basic needs approach does imply a selective approach to technology and in that sense it argues against the indiscriminate use of modern technology irrespective of its social profitability. More positively, in order to generate productive employment for all within a relatively short period of time, it requires widespread utilisation of a variety of forms of intermediate and other types of nonconventional technology. A selective combination of the capital and labour intensive technologies has been a hallmalk of the experience of most countries which have achicved rapid growth and eliminated unemployment in a relatively short period of time.

We come finally to the criticism that the basic needs approach in some sense runs counter to the NIEO.
Earlier, it was argued that no purpose is served by merging or confusing the two distinct concepts of basic needs and the NIEO. The former specifies what the objectives of development should be and elaborates policies and measures to attain them. The latter specifies the changes required in international economic institutions and policies and in relations between states to redress past injustices and to create a more equitable framework for the future. The fact, however, that the two concepts are distinct does not imply that they are unrelated. The most obvious link between the two is that the implementation of the provisions of the NIEO, through redistribution of wealth and income from rich to poor nations and through a more equitable pattern of international economic growth, would immediately and over time increase the resources available to poor countries to launch basic needs strategies and meet basic needs targets more effectively. But in the absence of internal reforms, the implementation of the NIEO will not in itself sulfice to meet the basic needs of the masses in the poor countries.

The two concepts arc also related through the international implications of the inplementation of basic needs strategies by developing countries. A basic nceds approach with its emphasis on selfreliance; on changes in patterns of demand, consumption and production; on utilisation of local material and human resources to produce goods and services to meet essential needs; on labour-intensive technologies and small-scale production, has implications for a wide range of international economic issues such as the stlucture and terms of trade, the transfer of technology, international migration, multinational enterprises and development assistance. A focus on meeting basic needs should imply a lessening of the dependence of the Third World on the markets, capital and technologies of the developed world; a greater potential for trade expansion among developing countries; an improvement in their terms of trade vis-à-vis the industrialised world; reduced dependence on multinationals and sophisticated technologies; a rcorientation of development assistance. All this should reduce the dependence of the developing countries on growth in the industrialised world and open up the possibility of autonomous, self-sustained growth for the Third World which is currently ruled out by their dependent status. The systematic pursuit of a basic needs strategy by developing countries would thus appear to be a potent means of accelerating the realisation of demands for a restrueturing of the world economy, though not necessarily always in the direction called for under the New International Economie Order. 